\title{
The Effect of Thermal Treatment on the Resistance of 7075 Aluminum Alloy in Aggressive Alkaline Solution
}

\author{
Alaba .O. Araoyinbo ${ }^{1 *}$, Mohd Mustafa Al Bakri Abdullah², Azmi Rahmat ${ }^{2}$, Azwan Iskandar \\ Azmi $^{1}$, Wan Mohd Faizal Wan Abd Rahim ${ }^{1}$, Noorina Hidayu Jamil ${ }^{1}$ and Tan Soo Jin ${ }^{1}$. \\ ${ }^{1}$ Faculty of Engineering Technology, Department of Mechanical Engineering Technology, Universiti \\ Malaysia Perlis, UniCity Alam, Sungai Chucho, Padang Besar, Perlis Malaysia. \\ ${ }^{2}$ Center of Excellence Geopolymer and Green Materials (CEGeoGTech), School of Materials \\ Engineering, Universiti Malaysia Perlis (UniMAP), Perlis, Malaysia
}

Received 4 February 2017; accepted 29 April 2018; available online 15 May 2018

DOI: https://10.30880/jst.2018.10.01.003

\begin{abstract}
Aluminum has attractive properties in which when properly engineered can be used in wider areas of applications. Due to its reactive abilities and strong affinity for oxygen, aluminum can resist rough environments and overall durable to various chemical agents. This work highlighted the behaviour of 7075 aluminum alloy in an aggressive alkaline environment. Two tempers of T6 and T73 were produced through solution heat treatment procedure; the T6 temper was subjected to solution heat treatment at $470^{\circ} \mathrm{C}$ for 60 min, quenched for $60 \mathrm{sec}$ and followed by precipitation heat treatment or artificial ageing at $138^{\circ} \mathrm{C}$ for 960 min whereas the T73 was subjected to solution heat treatment at $470^{\circ} \mathrm{C}$ for 60 min quenched for $60 \mathrm{sec}$ and followed by two precipitation heat treatment processes at $113^{\circ} \mathrm{C}$ for $480 \mathrm{~min}$ and $182^{\circ} \mathrm{C}$ for $720 \mathrm{~min}$ respectively. The as received and the tempered materials are immersed in an aggressive alkaline medium consisting sodium chloride and hydrogen peroxide. The samples obtained were characterized by assessing weight loss and subjected to surface morphology analysis using scanning electron microscope. The morphology of the heat treated samples shows the type of localized form of corrosion present is pitting form of corrosion, and the weight analysis shows significant weight loss when the samples are exposed to the aggressive alkaline environment. The weight loss for the as received sample was observed to be more than the $\mathrm{T} 73$ and the T6 samples.
\end{abstract}

Keyword: Alkaline medium; Aluminum alloy; Corrosion; Heat treatment; Weight loss.

\section{Introduction}

Aluminum remains as one of the most desired metallic materials because of its numerous application areas which include automobiles, aerospace, constructions etc. It also the third most abundant element constituting about $8.13 \%$ in the earth's crust and it mainly exists in very stable combinations with other materials (particularly as silicates and oxides) in nature [1]. Metals and alloys are the most important source of engineering materials, and the demand for this materials with improved properties (i.e. strength, ductility, light weight) is always on the increase with the ever advancement of science and technology. With high annual consumption rate of 8.1 million metric tons in Europe alone - aluminum is the world's most commonly used metals, it offers several advantages such as light weight with acceptable strength, high conductivity, and good corrosion resistance due to the presence of barrier oxide film layer [2,3].

For instance, aluminum's light weight performances are highly benefited in transport applications that are related to aerospace industry. The metal has been widely used as construction materials, heat exchangers, catalyst, combustion processes, and power lines [1].

The development of new alloys has been in progress throughout the history of aluminum, however the main issue of these metallic materials is the deterioration in its properties originated from the interaction with natural environment. These could lead to premature failure of metallic components and causes severe economic loss, as well as potential risk to human lives. The annual direct loss of natural resources i.e.- metals due to environmental degradation is also substantial and the degradation process varies 
from one medium to another [4-6]. Improving corrosion performance has been a key focus of this metallurgical development. Alloys are developed with good thermal conductivity, combined with excellent resistance to engine coolants. This combination means it was possible to manufacture heat exchangers that were cheaper and of course lighter than the traditional copper versions. More recently new alloy developments have included automotive, desalination of sea water, renewable energy and maritime applications and many industrial applications $[7,8]$. The 7000 series high strength aluminum alloys are used in aircraft structures because of their strength. The most commonly used alloy in aircraft manufacturing is AA7075. Due to the constant exposure of this alloy to the environment during in service operation, this research aims to investigate the corrosion resistance of 7075 aluminum alloy of the heat treated specimens of peak age and over age tempers. The surface morphology was also investigated to observe any change in the microstructure of the heat treated specimens produced after corrosion immersion test in an aggressive alkaline medium.

\section{Experimental Procedure Materials}

A 7075 aluminum alloy was purchased locally from Aluminium Company of

Malaysia Berhad for the sole purpose of this research with dimensions of $290 \times 50.8 \times 51 \mathrm{~mm}$. Specimens of dimensions $25 \times 30 \times 15 \mathrm{~mm}$ was cut from the bulk for analysis, and dimensions of $51 \times 17 \times 6 \mathrm{~mm}$ was cut for the heat treatment procedure and immersion test.

\section{Preparation}

The 7075 aluminum alloy specimens' surface were ground and polished to mirror finish utilizing 1200 grit abrasive papers and $0.5 \mu \mathrm{m}$ alumina powders. The heat treatment process was initiated by heat treatment at $470^{\circ} \mathrm{C}$ for 60 minutes and then quenched in water (at room temperature) for 60 seconds; the process was then followed by precipitation heat treatment. The peak aged, over aged was applied to the material in the T6 temper, and T73 temper at different durations and temperatures. The specimen in the T6 temper was subjected to solution heat treatment at $470^{\circ} \mathrm{C}$ for 60 minutes, quenched for
60 seconds and followed by precipitation heat treatment or artificial ageing at $138^{\circ} \mathrm{C}$ for 960 minutes. The specimen for the $\mathrm{T} 73$ was subjected to solution heat treatment at $470^{\circ} \mathrm{C}$ for 60 minutes quenched for 60 seconds and followed by two precipitation heat treatment processes at $113^{\circ} \mathrm{C}$ for 480 minutes and $182^{\circ} \mathrm{C}$ for 720 minutes respectively.

\section{Immersion Test}

Two heat treated specimens and one as received specimen were immersed in corrosive solution for four days. The $\mathrm{pH}$ of the environment was controlled and set at 9.26. Keller's reagent was used to clean the surface of the specimens prior to the immersion test.

\section{Aggressive Alkaline Medium pH9.2}

The peak aged T6, over aged T73 and as received (AR) were used in the aggressive alkaline medium containing $58.5 \mathrm{~g}$ sodium chloride, $3 \mathrm{~g}$ hydrogen peroxide and diluted to one litre with deionised water and immersed for 4 days according to American Society for Testing and Materials (ASTM) standards G110-92(2003) for corrosion resistance of heat treatable aluminum and aluminum alloys.

\section{Characterization}

The polished specimens was analysed using X-ray fluorescence (XRF) to determine the chemical compositions of 7075 aluminum alloy, the weight loss analysis by the immersion test, and the surface microstructure by scanning electron microscope (SEM).

\section{Results and discussion}

\section{Chemical Analysis}

The characterization of the as received sample with the X-ray fluorescence (XRF) tool gives a quantitative analysis result of the chemical compositions of the received sample to be compared with the standard chemical compositions for 7075 aluminum alloy which is presented below in Table 1 . 
Table 1 Chemical composition of 7075 aluminum alloy

\begin{tabular}{|c|c|c|}
\hline \multirow{2}{*}{ ELEMENTS } & \multicolumn{2}{|c|}{ WEIGHT PERCENT (wt \%) } \\
\hline & $\begin{array}{l}\text { SAMPLE } \\
\text { COMPOSITION }\end{array}$ & $\begin{array}{l}\text { STANDARD } \\
\text { COMPOSITION }\end{array}$ \\
\hline $\begin{array}{l}\text { Aluminum } \\
\text { (Al) }\end{array}$ & 90 & 90.07 \\
\hline $\begin{array}{l}\text { Magnesium } \\
\text { (Mg) }\end{array}$ & 2.7 & 2.5 \\
\hline $\begin{array}{l}\text { Silicon } \\
\text { (Si) }\end{array}$ & 0.17 & N/A \\
\hline $\begin{array}{c}\text { Titanium } \\
\text { (Ti) }\end{array}$ & 0.023 & N/A \\
\hline $\begin{array}{l}\text { Chromium } \\
\text { (Cr) }\end{array}$ & 0.16 & 0.23 \\
\hline $\begin{array}{c}\text { Manganese } \\
\text { (Mn) }\end{array}$ & 0.011 & N/A \\
\hline $\begin{array}{l}\text { Iron } \\
(\mathrm{Fe})\end{array}$ & 0.16 & N/A \\
\hline $\begin{array}{l}\text { Nickel } \\
\text { (Ni) }\end{array}$ & Trace & N/A \\
\hline $\begin{array}{l}\text { Copper } \\
\text { (Cu) }\end{array}$ & 1.5 & 1.6 \\
\hline $\begin{array}{l}\text { Zinc } \\
\text { (Zn) }\end{array}$ & 5.0 & 5.6 \\
\hline $\begin{array}{l}\text { Gallium } \\
\text { (Ga) }\end{array}$ & Trace & N/A \\
\hline $\begin{array}{l}\text { Zirconium } \\
(\mathrm{Zr})\end{array}$ & 0.013 & N/A \\
\hline
\end{tabular}

\section{Heat treated specimen at pH9.2}

Fig. 1(a) and (b), Fig. 2 (a) and (b), and Fig. 3(a) and (b) shows the type of localized corrosion present on the aluminum alloys when exposed to a more severe alkaline medium which turns out to be the pitting form of corrosion. The exposed surfaces present a severe localized form of corrosion for the different specimens. The attack on the exposed surface appears to be severe for the as received (AR) (see Fig. 1 (a) and (b)), T6 (see Fig. 2 (a) and (b)), and T73 (see Fig. 3 (a) and (b)) specimens regardless of the difference in the solution heat treatment procedure. The effect of the chemical attack on the different specimens' can be clearly seen in Table 2. The AR specimen recorded more weight loss $(0.5882 \mathrm{~g})$ when compared to the T6 $(0.4279 \mathrm{~g})$ and T73 $(0.4387 \mathrm{~g})$ heat treated specimens after exposure to the corrosion medium. This confirms the following that in solutions containing chloride ions, pitting corrosion is the main form of localized corrosion expected to be present [9-13]. As the pits grow into the microstructure, they can develop into intergranular corrosion (IGC) or exfoliation (a form of IGC found in wrought $\mathrm{Al}$ alloys), which can penetrate deeply into the surface of the sample. To some extent, IGC can be regarded as a special kind of pitting corrosion occurring preferentially at the grain boundaries for $\mathrm{Al}$ alloys since the mechanism of IGC was found to be of the same nature as the process of pitting.
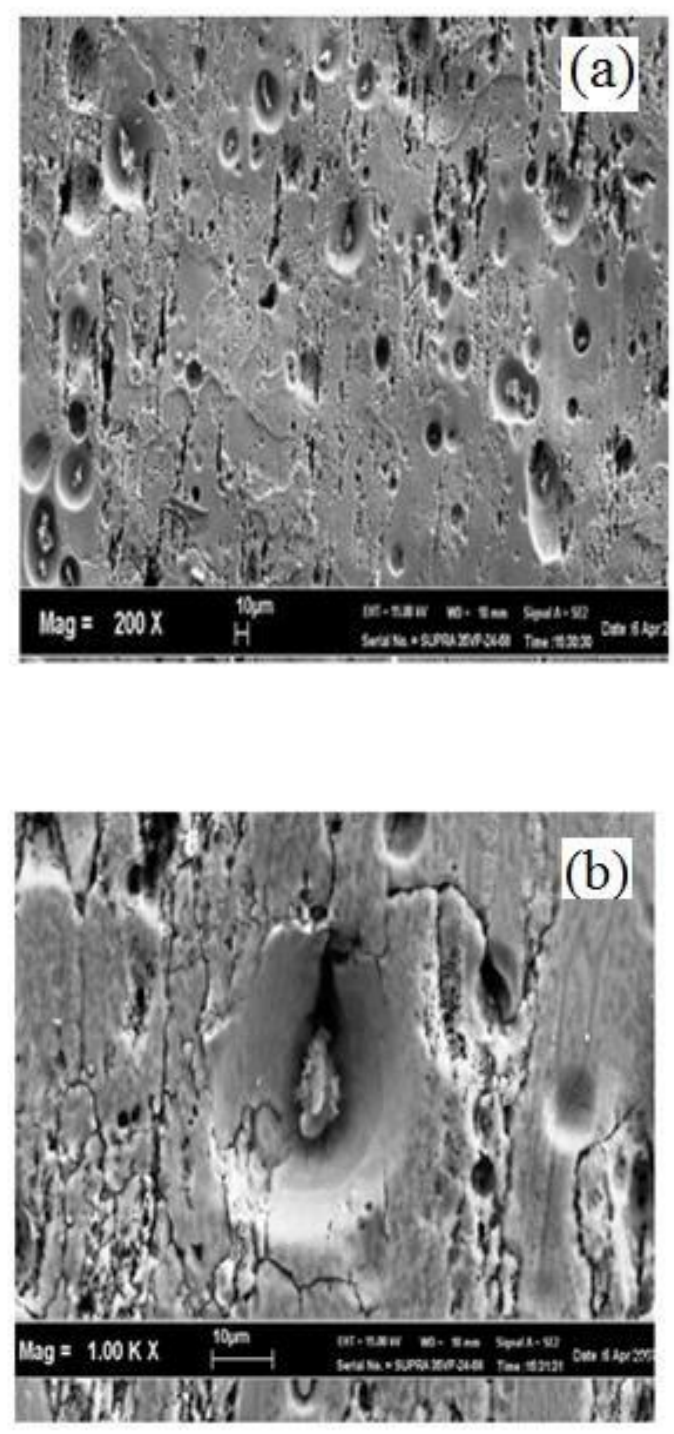

Fig. 1 Scanning electron microscope (SEM) of AR showing pitting corrosion attack for (a) 200x magnification and (b) 1000x magnification. 

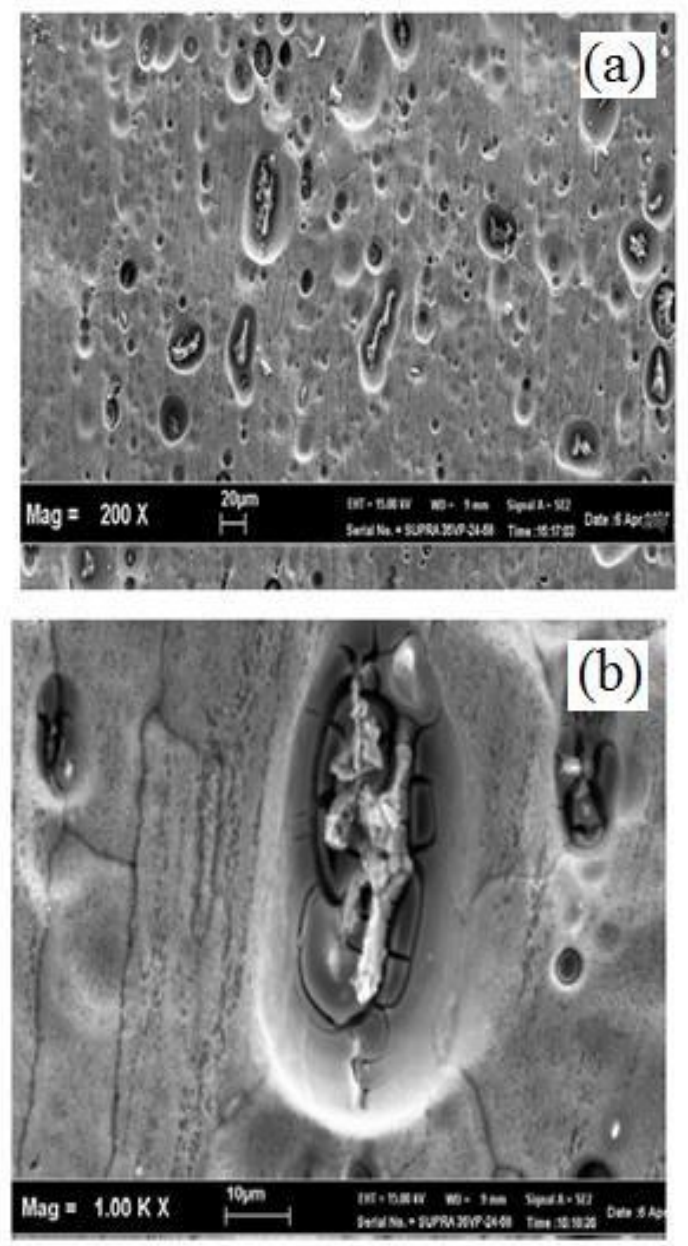

Fig. 2 Scanning electron microscope (SEM) of T6 showing pitting corrosion attack for (a) 200x magnification, and (b) 1000× magnification.

Table 2 shows the weight losses and corrosion rate for $\mathrm{AR}, \mathrm{T} 73$, and $\mathrm{T} 6$ immersed in a test solution at $\mathrm{pH} 9.2$ for 4 days. The weight loss obtained for the three different specimens in the aggressive alkaline solution are $0.5882 \mathrm{~g}(\mathrm{AR})$, $0.4387 \mathrm{~g}$ (T73), and $0.4279 \mathrm{~g}$ (T6). These show that regardless of the heat treatment solution if the material is unprotected, the deterioration and weight loss becomes rapid that can lead to material failure when in an aggressive alkaline environment. The problem of pitting and IGC susceptibility in high strength $\mathrm{Al}$ alloys has been studied for many years. In principle, both pitting and IGC result from a local breakdown of the passive film that forms on the surface. The attack that occurs at intermetallic particles or in the matrix of a grain is called pitting, whereas attack restricted to grain boundary (GB) regions is called intergranular corrosion (IGC). From an electrochemical point of view, both pitting and
IGC processes seem to be very similar in nature [14-18].
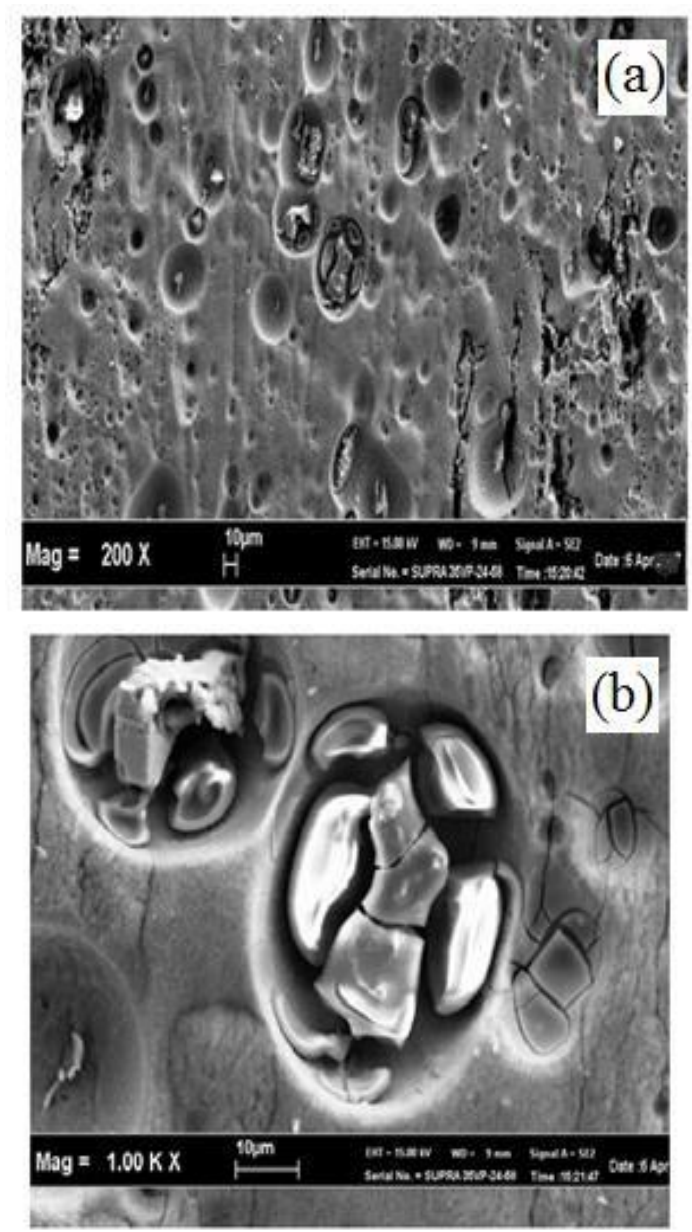

Fig. 3 SEM of T73 showing pitting corrosion attack for (a) 200× magnification, and (b) $1000 \times$ magnification.

Table 2 Weight losses and corrosion rate test result at $\mathrm{pH} 9.2$

\begin{tabular}{|c|c|c|c|c|c|c|}
\hline Specimen & $\begin{array}{l}\text { Initial } \\
\text { weight } \\
\text { (g) }\end{array}$ & $\begin{array}{c}\text { Duration } \\
\text { (days) }\end{array}$ & $\begin{array}{l}\text { Final } \\
\text { weight } \\
\text { (g) }\end{array}$ & $\begin{array}{l}\text { Weight } \\
\text { loss } \\
(\mathrm{g})\end{array}$ & Solution & $\begin{array}{c}\text { Corrosion } \\
\text { rate } \\
(\mathrm{mm} / \mathrm{rr})\end{array}$ \\
\hline AR & 17.4437 & 4 & 16.8555 & 0.5882 & $\begin{array}{l}\mathrm{NaCl} \\
\mathrm{H}_{2} \mathrm{O}_{2} \\
\end{array}$ & 22.11 \\
\hline$T 73$ & 19.1598 & 4 & 18.7211 & 0.4387 & $\begin{array}{l}\mathrm{NaCl} \\
\mathrm{H}_{2} \mathrm{O}_{2}\end{array}$ & 16.49 \\
\hline T6 & 18.8019 & 4 & 18.3740 & 0.4279 & $\begin{array}{l}\mathrm{NaCl} \\
\mathrm{H}_{2} \mathrm{O}_{2}\end{array}$ & 16.08 \\
\hline
\end{tabular}




\section{Conclusion}

Aluminum when exposed to the environment forms a protective barrier oxide film between the metal and the surrounding medium. The physicalchemical stability of the oxide film determines the corrosion resistance. Due to the surface thin oxide film, the corrosion behaviour of the aluminium alloy in an aggressive medium shows rapid deterioration and formation of pits on the surface of the material. The formation of these pits from AR, T73 and T6 is due to the passive film breakdown and rapid chemical attack on the aluminium alloy surface. The presence of these pits is observed in all the three specimens and they all experienced significant weight losses but the as received specimen experienced more weight loss than the tempered alloys. The significant difference in all the specimens is that the heat treatment procedure assisted in the reduction of the weight loss experienced from the immersion test. This is due to the microstructure of the heat treated specimens, which was able to reduce the effect of the localized pitting corrosion attack on the surface of the materials.

\section{Acknowledgments}

The authors would like to express gratitude to Universiti Malaysia Perlis (UniMAP), Center of Excellence Geopolymer and Green Materials (CEGeoGTech) for providing the opportunity to be involved in this project. References

[1] Christian, V. (2004) Corrosion of Aluminum, Elsevier Ltd, the Boulevard Langford Lane Kidlington Oxford OX 5 IGB, UK.

[2] Callister, W. D. (2007) Materials science and Engineering: An Introduction. 7th Edition John Wiley \& Sons.

[3] Inemesit, A. A. \& Nnanake, A.O.O. (2013) Inhibition of Mild Steel Corrosion in Hydrochloric Acid Solution by Ciprofloxacin Drug. International Journal of Corrosion, pp. 1-5.

[4] Singh, I.B. \& Chakradhar, B. (2013)

Effect of $\mathrm{pH}$ and Hardness on the

Scale Formation of Mild Steel in

Bicarbonate ion Containing Water. Corrosion and its Controls, Vol. 1 \& 2. pp. 1009-1012.
Wei-Kang, L., Ronald, L.E. \& Bernhard, W. (1995) Corrosion Protection of Mild-Steel by Coatings Containing Polyaniline. Synthetic Metals, Vol. 71. No. 1 - 3 pp. 2163-2166.

[6] Boudalia, M., Sebbar, N.K.,

Bourazmi, H., Lahmidi, S., Ouzidan, Y., Essassi, E.M., Tayebi, H., Bellaouchou, A., Guenbour, A. \& Zarrrouk, A. (2016) Anti-Corrosive Properties of New Benzothiazine Derivative on Mild Steel Corrosion in

$1 \mathrm{M} \mathrm{HCl}$ : Experimental and Theoretical Investigations. Journal of Materials and Environmental Science, Vol. 7. No. 3 pp. 878-888.

[7] Malarvizhi, M., Dheenadhayalan, S., Brindha, T. \& Mallika, J. (2016) Corrosion Inhibition of Mild Steel in 1 mol L ${ }^{-1} \mathrm{HCl}$ Using Gum Exudates of Azadirachta indica. Advances in Physical Chemistry, pp. 1-12.

[8] Ehteram, A.N. \& Aisha H.A. (2008)

Corrosion Behaviour of Mild Steel in

Hydrochloric Acid solutions. International Journal of

Electrochemical Science, pp. 806-818.

[9] Onukwube, N. D., Awomukwu, D. A. \& Brown, N. (2016) Inhibition Of Corrosion Of Mild Steel In Alkaline Medium By Ethanol Extract Of Pterocarpus Soyauxii Taub Leaves. Ewemen Journal of Analytical \& Environmental Chemistry, Vol. 2. pp. 3844.

[10] Rokuro, N., Achmad, S. \& Yasuaki, M. (2003) Stress Corrosion Cracking Susceptibility of Sensitized type 316 Stainless Steel in Sulphuric Acid Solution. Corrosion Science, Vol. 45. No. 2 pp. 465-484.

[11] Saratha, R., Priya, S.V. $\&$

Thilagavathy, P. (2009) Investigation of Citrus Aurantiifolia Leaves Extract as Corrosion Inhibitor for Mild Steel in $1 \mathrm{M} \mathrm{HCl}$. E- Journal of Chemistry, Vol. 6. No. 3 pp. 785-795.

[12] Wen-Ta, T. \& Ming-Shan, C. (2000) Stress Corrosion Cracking Behavior of 2205 Duplex Stainless Steel 
in Concentrated $\quad \mathrm{NaCl}$

Solution.

Corrosion Science, Vol. 42. pp 545- 559.

[13] Al-Amiery, AA., Kadhum, A.A.H., Alobaidy, A.H.M., Mohamad, A.B. \& Hoon, P.S. (2014) Novel Corrosion Inhibitor for Mild Steel In HCl. Materials (Basel), Vol. 7. No. 2 pp 662-672.

[14] Chauhan, L.R. \& Gunasekaran, G. (2007) Corrosion Inhibition Of Mild Steel by Plant Extract in Dilute $\mathrm{HCl}$ Medium. Corrosion Science, Vol. 49. pp 1143-1161.

[15] Kazem, S.B., Changiz, D. \& Saeed, Y. (2017) Corrosion Inhibition of Copper, Mild Steel and Galvanically Coupled Copper-Mild Steel in Artificial Sea Water in Presence of 1H-Benzotriazole, Sodium Molybdate and Sodium Phosphate. Corrosion Science, Vol. 126. pp 272-285.

[16] Makanjuola, O., Ebitei, C., Collins, A. \& Tambari, K. (2011) Corrosion Inhibition Of Mild Steel In

Hydrochloric Acid By Tannins Rom Rhizophora Racemosa, Materials Sciences and Applications, Vol. 2. pp 592-595.

[17] Olajire, A. A. (2017) Corrosion Inhibition of Offshore Oil and Gas Production Facilities Using Organic Compound Inhibitors. Journal of Molecular Liquids, Vol. 248, 775808.

[18] Kissell, \& R. \& Ferry R. (2002) Aluminum Structures a Guide to their Specifications and Design, $2^{\text {nd }}$ Ed, New York: J. Wiley. 